\title{
Bioinspired Asymmetric Total Synthesis of Emeriones A-C
}

\author{
[*] S. Jänner, D. Isak, and Dr. A. K. Miller \\ Cancer Drug Development Group \\ German Cancer Research Center (DKFZ) \\ Im Neuenheimer Feld 280, Heidelberg, Germany \\ E-mail: aubry.miller@dkfz.de \\ [+] These authors contributed equally to this work
}

Sven Jänner, ${ }^{+}$Daniel Isak, ${ }^{+}$and Aubry K. Miller*

\begin{abstract}
We report an asymmetric bioinspired total synthesis of the fungal metabolites emeriones $\mathrm{A}-\mathrm{C}$ via stereoselective late-stage epoxidation or endoperoxidation of two bicyclo[4.2.0]octadiene diastereomers. The central bicyclic scaffold is synthesized in an $8 \pi / 6 \pi$ electrocyclization cascade of a stereodefined $(E, E, Z, Z, E)$ pentaene, which contains the fully assembled and unprotected side chains of the natural products. The pentaene is constructed convergently through Stille cross-coupling of two similarly complex polyenes. The anti-aldol side chain of the emeriones is made using a Paterson-aldol approach, and the epoxide of the dioxobicyclo[3.1.0] side chain is synthesized via an unusual ring-closure onto an oxidized para-methoxyphenyl acetal. Our total synthesis has enabled the revision of the structure of emerione $\mathrm{C}$ and the synthesis of a "missing" family member, which we hereby call emerione D.
\end{abstract}

Natural products derived from polyenes that undergo cyclization/isomerization cascades initiated by an $8 \pi$-electrocyclization have intrigued chemists for decades. ${ }^{[1]}$ Comprising an ever-growing diversity of biologically active structures, such compounds have been isolated from a variety of species in many parts of the world. The emeriones (Figure 1), one such family of natural products that were recently isolated from the fungus $E$. nidulans, ${ }^{[2]}$ display oxidized bicyclo[4.2.0]octadiene cores (red) flanked by a seven carbon aldol fragment (blue) and a propenyl-substituted dioxobicyclo[3.1.0] system (black). The aldol and dioxobicyclo[3.1.0] side chains of emerione A (1) and B (2) share the same absolute configurations, while the bicyclo[4.2.0]octadieneoxide central scaffolds are enantiomeric with respect to each other. Emerione C contains an endoperoxide on the central core as opposed to an epoxide, and its proposed structure has the same carbon backbone stereochemistry as emerione B.

Related natural products like shimalactone $A(3)^{[10]}$ and ocellapyrone $B(4)^{[11,1 \mathrm{~m}]}$ have been prepared by total synthesis, but the emeriones are arguably the most complex examples of such natural products, each containing twelve stereocenters, eight of which are contiguous, and two of which are quaternary. Moreover, the dioxobicyclo[3.1.0] sidechain substructure, also found in natural products like veruccosidin (5), ${ }^{[3]}$ represents a distinct synthetic challenge alongside the oxidized bicyclo[4.2.0]octadiene scaffolds. Emerione A (1) inhibits NO production in lipopolysaccharide-induced RAW264.7 cells at low micromolar concentrations, but the emeriones appear not to have been tested in other biological assays. Motivated both by their striking chemical structures and their potentially undiscovered biological activities, we chose to target the emeriones for total synthesis. We describe herein the successful
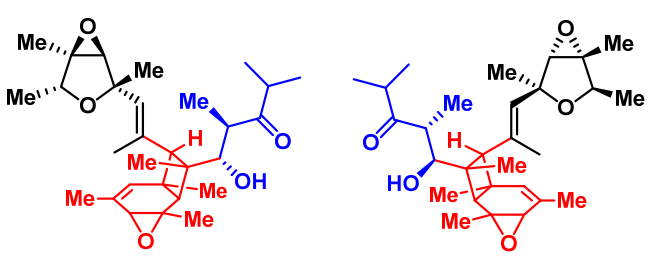

emerione A (1)

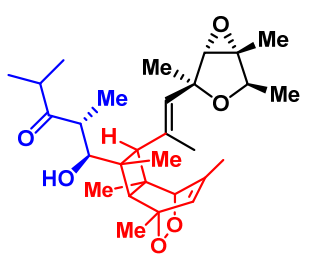

emerione $\mathbf{C}$

proposed

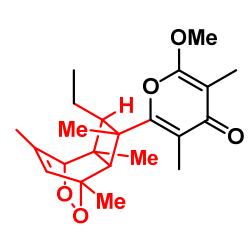

ocellapyrone B (4)

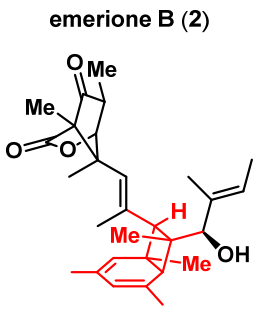

shimalactone A (3)

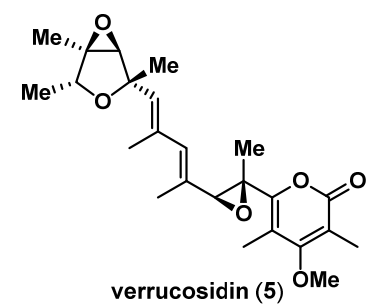

Figure 1. Representative natural products containing an oxidized bicyclo[4.2.0]octadiene core.

synthesis of all three emeriones, the structural revision of emerione $\mathrm{C}$, and the synthesis of the originally proposed structure of emerione $\mathrm{C}$, which we have named emerione $\mathrm{D}$.

It is plausible that the emeriones are biosynthetically derived from the highly unsaturated heptaene polyketide $\mathbf{6}$, which after two oxidations at the alkenyl terminus gives a diastereomer (7) of the proposed structure of the natural product emecorrugatin $B(8)$ (Figure 2, top). ${ }^{[4][5]}$ Two E/Z double-bond isomerizations then generate $(E, E, Z, Z, E)$-pentaene $\mathbf{9}$, which is geometrically poised to undergo an $8 \pi / 6 \pi$ electrocyclization cascade. ${ }^{[6]}$ This provides two bicyclo[4.2.0]octadienes (10/11), which after epoxidation or endoperoxidation give the emeriones. In our retrosynthesis (Figure 2, bottom), we modeled the late stages of our approach on the proposed biosynthesis, reasoning that the necessary chemo and stereoselective oxidations would be inherently favored and likely to succeed. Therefore, emeriones $A(1)$ and $B(2)$ would be synthetically derived from bicyclo[4.2.0]octadienes 10 and 11, respectively, via mono- 


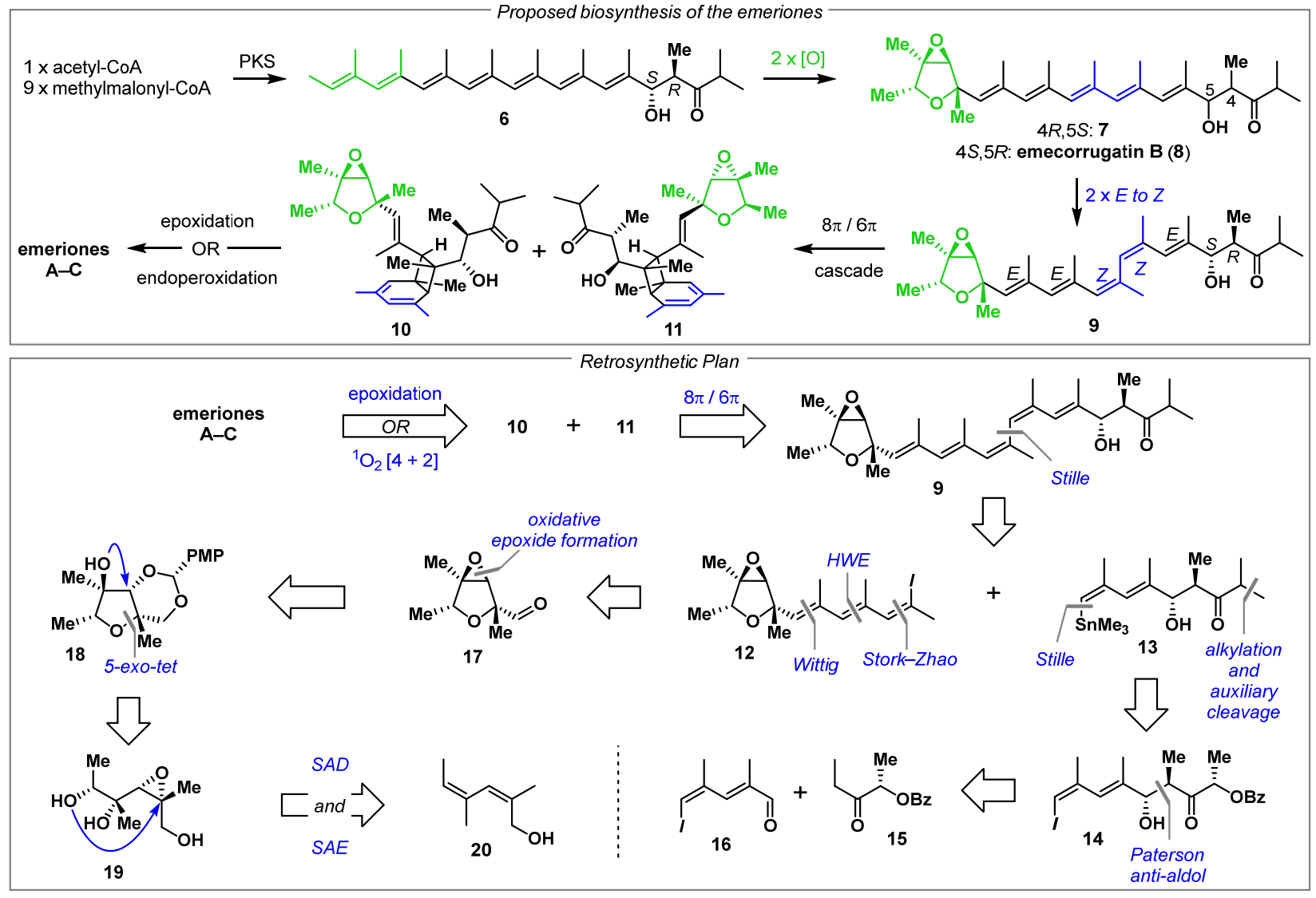

Figure 2. Proposed biosynthesis (top) and retrosynthetic plan (bottom).

epoxidations, and the endoperoxide emerione $\mathrm{C}$ would be traced back to 11 via [4+2] cycloaddition with ${ }^{1} \mathrm{O}_{2}$. While endoperoxides like ocellapyrone B (4) have been synthesized in a similar manner, ${ }^{[1 k, 11]}$ to the best of our knowledge, no selective mono-epoxidations on related bicyclo[4.2.0]octadiene systems have been previously demonstrated. Bicyclo[4.2.0]octadienes 10 and 11 would arise from pentaene 9 through an $8 \pi / 6 \pi$ electrocyclization cascade, presumably forming only two of the four possible Woodward-Hoffmann-compatible stereoisomers. At this point diverging from a biomimetic approach, pentaene $\mathbf{9}$ would be stereoselectively constructed in a convergent Stille coupling of iodide 12 and stannane 13. Stannane 13 could be derived from iodide 14 , which would be prepared in a Paterson anti-aldol addition of aldehyde 16 and enantioenriched ketone $15{ }^{[7]}$ lodide 12 can be traced back to aldehyde 17 through a series of stereoselective olefination reactions. The trisubstituted epoxide of 17 would be formed via oxidation of paramethoxyphenyl acetal 18, which in turn could be derived from epoxytriol 19. Sequential asymmetric epoxidation and dihydroxylation reactions would generate 19 from $(Z, Z)$-dienol 20.

Our synthesis began with iodoalcohol 22, which can be prepared in multi-gram scale in four steps from propargyl alcohol (21) (Scheme 1A). ${ }^{[1 \mathrm{k}]}$ Aldehyde 23, synthesized by $\mathrm{MnO}_{2}$ oxidation of 22, was found to be prone to isomerization/decomposition and was therefore always used immediately after preparation. Reaction of $\mathbf{2 3}$ in a Paterson aldol addition with the $E$-configured boron enolate of ketone $\mathbf{2 4}$ gave 25 with >95:5 diastereomeric ratio. The relative and absolute configuration of $\mathbf{2 5}$ was confirmed via X-ray crystallography. Silyl protection of the secondary hydroxyl group gave $\mathbf{2 6}$ and was followed by removal of the benzoate chiral auxiliary via $\mathrm{Sml}_{2}$ in $\mathrm{MeOH}^{\left[{ }^{[8][9]}\right.}$ The resulting ethyl ketone (27) was converted smoothly to isopropyl ketone $\mathbf{2 8}$ via kinetic enolate formation and subsequent treatment with methyl iodide. Removal of the TBS-silyl protecting group to cleanly give $\mathbf{2 9}$ could only be realized with $\mathrm{HF}$, and $\mathrm{HF} \cdot$ pyridine performed better than $\mathrm{HF} \cdot \mathrm{Et}_{3} \mathrm{~N}$; other fluoride sources resulted in significant retro-aldol reaction, and the deprotection was very slow under acidic conditions. Stille reaction of 29 with $\mathrm{Me}_{6} \mathrm{Sn}_{2}$ then gave coupling partner 13. As 13 readily undergoes protodestannylation, material was typically stockpiled as iodide $\mathbf{2 9}$.

The synthesis of iodide 12 began with two step conversion of methyl angelate (30) into angelic aldehyde, which was found to be configurationally labile (Scheme 1B). ${ }^{[10]}$ Therefore, after preparation, it was always immediately used in a Still-Gennari olefination with phosphonate $\mathbf{3 1}$ to give dienoate $\mathbf{3 2}$, which was subsequently reduced with DIBAL to give allylic alcohol 20. . $^{[1][12]}$ We were surprised that neither $\mathbf{3 2}$ nor $\mathbf{2 0}$ are previously described compounds. Sharpless asymmetric epoxidation of $\mathbf{2 0}$ proceeded in excellent yield to give 33, but with modest 

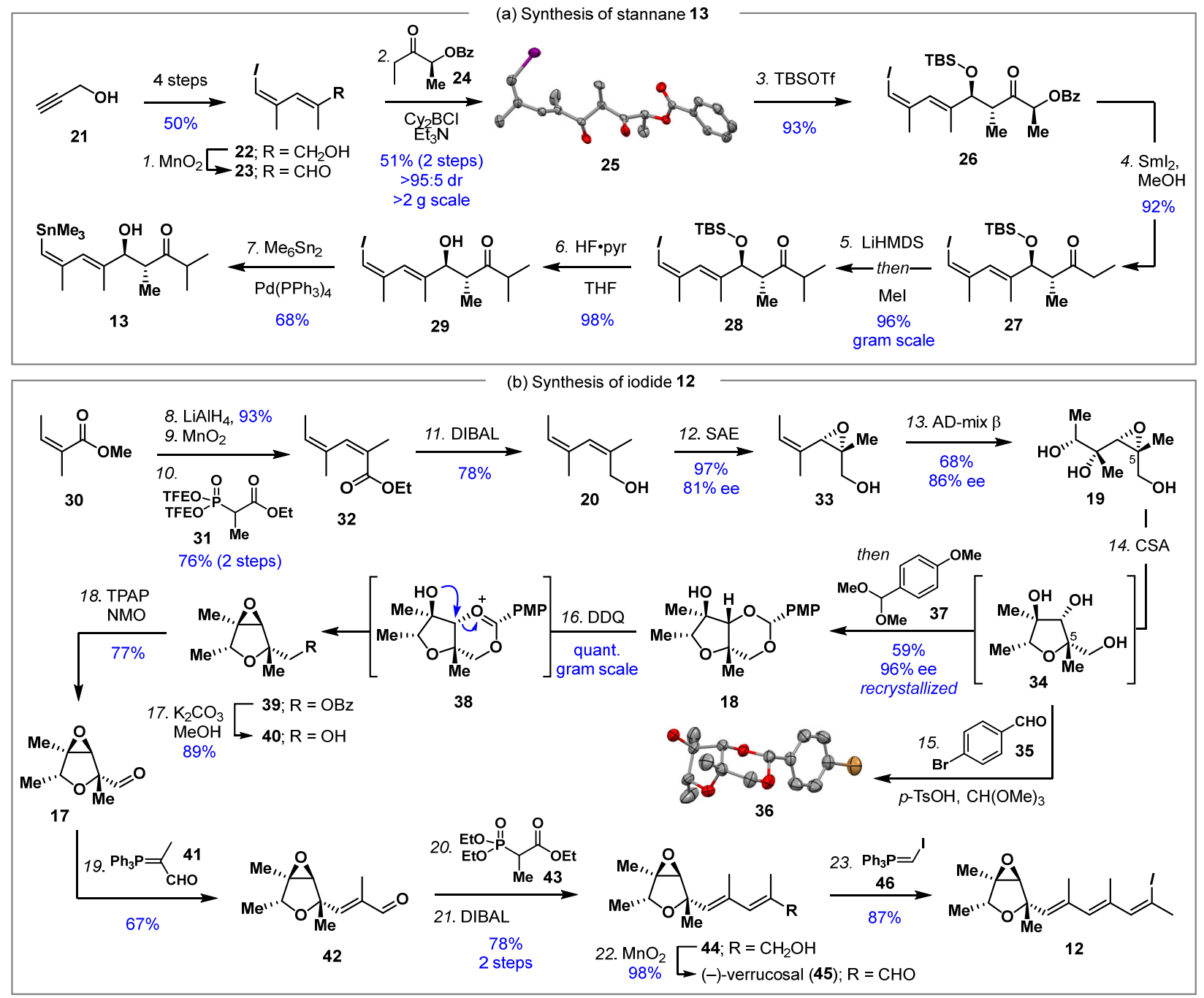

Scheme 1. Synthesis of the cross-coupling partners 12 and 13. Reagents and conditions: 1. $\mathrm{MnO}_{2}\left(21\right.$ equiv), $\mathrm{CH}_{2} \mathrm{Cl}_{2}, \mathrm{rt}, 30 \mathrm{~min} ; 2 . \mathrm{Cy}_{2} \mathrm{BCl}$ (1.8 equiv), $\mathrm{Et}{ }_{3} \mathrm{~N}(2.2$ equiv), 24 (1.6 equiv), $\mathrm{Et}_{2} \mathrm{O},-78^{\circ} \mathrm{C} \rightarrow 0{ }^{\circ} \mathrm{C}$ then 23 (1.0 equiv), $-78^{\circ} \mathrm{C} \rightarrow-20{ }^{\circ} \mathrm{C}, 51 \%$ ( 2 steps); 3 . TBSOTf (3.1 equiv), 2,6 -lutidine $\left(4.3\right.$ equiv), $\mathrm{CH}_{2} \mathrm{Cl}{ }_{2}-78{ }^{\circ} \mathrm{C}$, $4.5 \mathrm{~h}, 93 \% ; 4 . \mathrm{Sml}_{2}$ (4.0 equiv), THF/MeOH, $0{ }^{\circ} \mathrm{C}, 1 \mathrm{~h}, 92 \% ; 5$. LiHMDS (2.0 equiv), THF, $-78{ }^{\circ} \mathrm{C}$, then Mel $\left(3.0\right.$ equiv), $1.5 \mathrm{~h}, 96 \% ; 6 . \mathrm{HF} \cdot \mathrm{py} / \mathrm{THF}(1: 4), 0{ }^{\circ} \mathrm{C} \rightarrow \mathrm{rt}$, $18 \mathrm{~h}, 98 \%$; 7. $\mathrm{Pd}\left(\mathrm{PPh}_{3}\right)_{4}(5 \mathrm{~mol} \%), \mathrm{Sn}_{2} \mathrm{Me}_{6}\left(1.2\right.$ equiv), THF, $80{ }^{\circ} \mathrm{C}, 5 \mathrm{~h}, 68 \%$; $8 . \mathrm{LiAlH}_{4}\left(2.5\right.$ equiv), THF, $0{ }^{\circ} \mathrm{C} \rightarrow \mathrm{rt}, 2 \mathrm{~h}, 93 \% ; 9 . \mathrm{MnO}_{2}\left(16.5\right.$ equiv), $\mathrm{CH} \mathrm{Cl}_{2}, \mathrm{rt}$, $18 \mathrm{~h} ; 10.31$ (1.1 equiv), KHMDS (1.1 equiv), 18-crown-6 (3.0 equiv), THF, $-78^{\circ} \mathrm{C}, 1 \mathrm{~h}$, then aldehyde $\left(1.0\right.$ equiv), $-78{ }^{\circ} \mathrm{C}, 1 \mathrm{~h}, 76 \%$ ( 2 steps); $11 . \mathrm{DIBAL}$ (2.7 equiv), $\mathrm{CH}_{2} \mathrm{Cl}_{2}, 0{ }^{\circ} \mathrm{C}, 1 \mathrm{~h}, 78 \% ; 12$. Ti(Oi-Pr) 4 (0.23 equiv), (-)-DET (0.27 equiv), $4 \AA \mathrm{MS}, \mathrm{CH}_{2} \mathrm{Cl}_{2},-25^{\circ} \mathrm{C}, 0.5 \mathrm{~h}$, then TBHP $(2.2 \mathrm{equiv}),-25^{\circ} \mathrm{C}, 0.5 \mathrm{~h}$, then 20 (1.0 equiv), $-40{ }^{\circ} \mathrm{C}, 24 \mathrm{~h}, 97 \%, 81 \%$ ee; 13 . AD-mix $\beta$ (10 mass equiv), $\mathrm{MeSO}_{2} \mathrm{NH}_{2}$ (1.0 equiv), $t$ - $\mathrm{BuOH} / \mathrm{H}_{2} \mathrm{O}(1: 1), 0{ }^{\circ} \mathrm{C}, 18 \mathrm{~h}, 68 \%, 86 \%$ ee; $14 . \mathrm{CSA}(0.1$ equiv), $\mathrm{CH}_{2} \mathrm{Cl}_{2}, 0{ }^{\circ} \mathrm{C}, 20 \mathrm{~h}$, then 37 (1.5 equiv), $0{ }^{\circ} \mathrm{C} \rightarrow \mathrm{rt}, 4 \mathrm{~h}, 59 \%, 96 \%$ ee (recrystallized); 15.35 (1.0 eq), p-TsOH (0.2 eq), $\mathrm{HC}(\mathrm{OMe}){ }_{3}(1.1 \mathrm{eq}), \mathrm{THF} ; 16 . \mathrm{DDQ}$ (1.3 equiv), $4 \AA \mathrm{MS}, \mathrm{DCE}, 80^{\circ} \mathrm{C}, 2 \mathrm{~h}$, quant.; $17 . \mathrm{K}_{2} \mathrm{CO}_{3}\left(6.0\right.$ equiv), $\mathrm{MeOH}, 0{ }^{\circ} \mathrm{C} \rightarrow \mathrm{rt}, 2 \mathrm{~h}, 89 \% ; 18 . \mathrm{TPAP}\left(0.05\right.$ equiv), $\mathrm{NMO}(1.5 \mathrm{equiv}), 4 \AA \mathrm{MS}, \mathrm{CH} \mathrm{Cl}_{2}, \mathrm{rt}, 1.5 \mathrm{~h}$, $77 \% ; 19.41$ (1.04 equiv), THF, $100{ }^{\circ} \mathrm{C}$ ( $\mu$-wave), $2 \mathrm{~d}, 67 \% ; 20.43$ (1.2 equiv), LiOt-Bu (1.2 equiv), THF, $0{ }^{\circ} \mathrm{C} \rightarrow \mathrm{rt}, 1 \mathrm{~h}$, then 42 (1.0 equiv), THF, rt, $3 \mathrm{~h},>95: 5 \mathrm{dr} ;$ 21. DIBAL (3.5 equiv), $\mathrm{CH}_{2} \mathrm{Cl}_{2}, 0{ }^{\circ} \mathrm{C}, 3 \mathrm{~h}, 78 \%$ (2 steps); $22 . \mathrm{MnO}_{2}$ (25 equiv), $\mathrm{CH}_{2} \mathrm{Cl}_{2}, \mathrm{rt}, 2.5 \mathrm{~h}, 98 \% ; 23 . \mathrm{Ph}_{3} \mathrm{PEt} \mathrm{t}^{+}-\left(4.0\right.$ equiv), $n$-BuLi, $\left(4.0\right.$ equiv), $\mathrm{THF}, 0{ }^{\circ} \mathrm{C} \rightarrow \mathrm{rt}$, $30 \mathrm{~min}$, then $\mathrm{I}_{2}$ (4.0 equiv), THF, $-78^{\circ} \mathrm{C}, 10 \mathrm{~min}$, then NaHMDS (3.8 equiv), THF, $-78{ }^{\circ} \mathrm{C}, 10 \mathrm{~min}$, then 45 ( 1.0 equiv), THF, $-78{ }^{\circ} \mathrm{C}, 2 \mathrm{~h}, 87 \%,>95: 5 \mathrm{dr}$. The ellipsoids in the experimental structures of $\mathbf{2 5}$ and $\mathbf{3 6}$ are depicted at a $50 \%$ probability level. ${ }^{[13]}$ Color code: carbon, grey; oxygen, red; iodine, purple, bromine, gold.

enantioselectivity (81\% ee), ${ }^{[14]}$ as has previously been observed with Z-configured allylic alcohols. ${ }^{[15]}$ While Upjohn oxidation of epoxide 33 was moderately diastereoselective (72:28 dr), Sharpless asymmetric dihydroxylation (SAD) with AD-mix $\beta$ proceeded with an improved diastereomeric ratio of 86:14. Moreover, due to reagent control in the SAD reaction, 19 was isolated with a slightly increased ee of $86 \%$ (Scheme S1). ${ }^{[16]}$ Acid-catalyzed isomerization of unprotected triol 19 proceeded with inversion of stereochemistry at C5 to give tetrahydrofuran 34, with the appropriate vicinal anti-diol configuration for epoxide formation. ${ }^{[17]}$ After numerous attempts to avoid cumbersome protecting group manipulations while advancing 34 to aldehyde 17 (Scheme S2), we hypothesized that the epoxide ring in $\mathbf{1 7}$ could be formed via oxidation of an acetal like $18{ }^{[18]}$ We found that acetal formation was facile: treatment of triol $\mathbf{3 4}$ with 4-bromobenzaldehyde (35) under acidic conditions with 


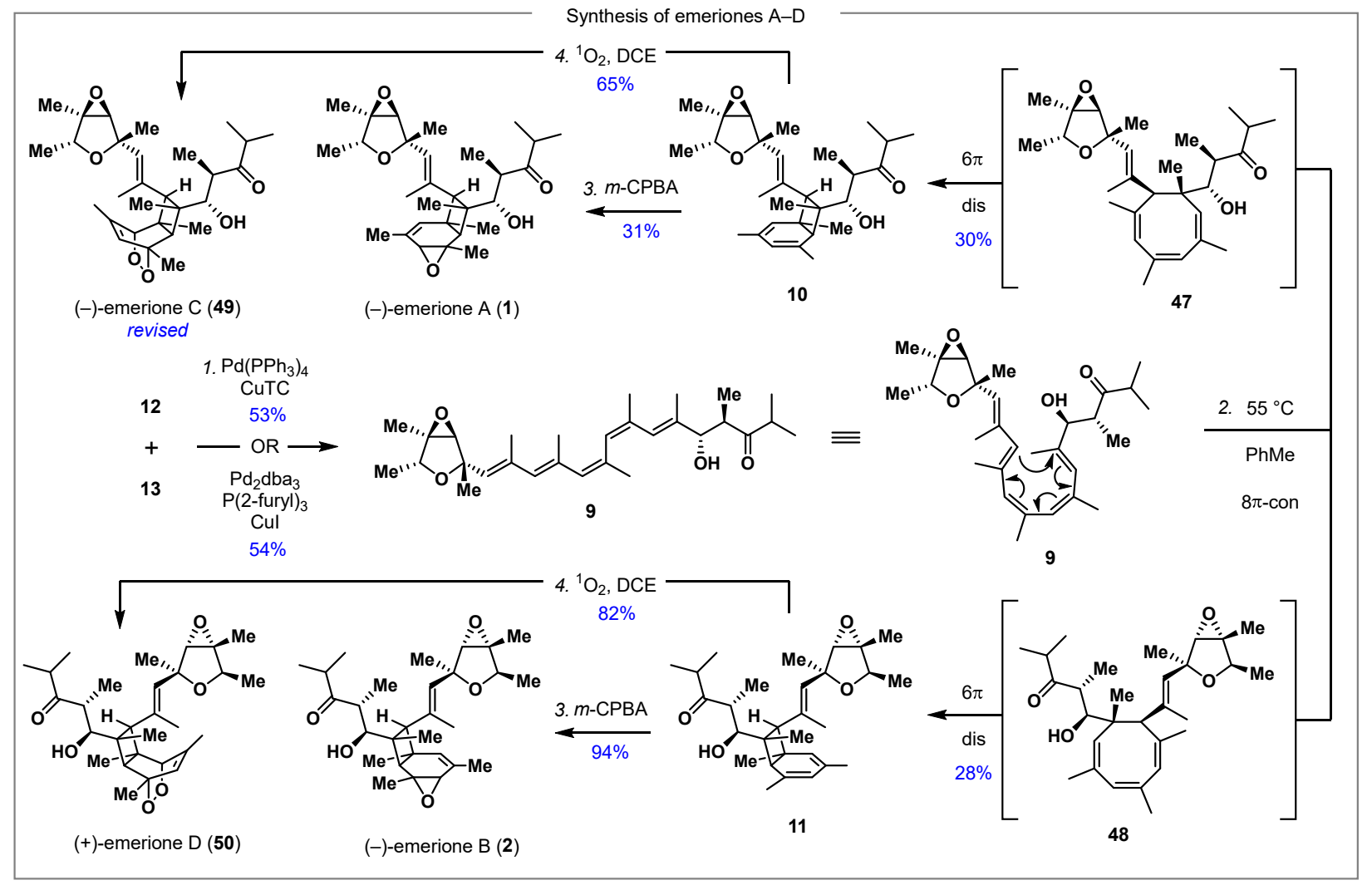

Scheme 2. Completion of the synthesis of the emeriones. Reagents and conditions: $1.12\left(1.0\right.$ equiv), $13(1.5$ equiv $), P d_{2}\left(d_{b a}\right)_{3}(0.12$ equiv $), P\left(2-f_{u r y l}\right)_{3}(0.48$ equiv), Cul (2.1 equiv), NMP, rt, 20 h, $54 \%$ OR 12 (1.0 equiv), 13 (1.5 equiv), $\mathrm{Pd}\left(\mathrm{PPh}_{3}\right)_{4}\left(0.10\right.$ equiv), CuTC (1.1 equiv), DMF, rt, $1 \mathrm{~h}, 53 \% ; 2 . \mathrm{PhMe}, 55{ }^{\circ} \mathrm{C}, 3 \mathrm{~d}$ 10: $30 \%, 11: 28 \%$; 3. $m$-CPBA (1.0 equiv), $\mathrm{NaHCO}_{3}$ (22 equiv), $\mathrm{CH}_{2} \mathrm{Cl}_{2} / \mathrm{H}_{2} \mathrm{O}(2: 1), 0{ }^{\circ} \mathrm{C} \rightarrow \mathrm{rt}, 45 \mathrm{~min}, 1: 31 \%, 2: 94 \% ; 4 . \mathrm{O}_{2}$, methylene blue (0.03 equiv), hv, $\mathrm{DCE}$, $10 \mathrm{~min}$, 49: $65 \%, 50: 82 \%$.

trimethylorthoformate as a dessicant gave $\mathbf{3 6}$, whose absolute and relative configuration was confirmed via $X$-ray crystallography. Taking note that the preceding THF-forming ring closure reaction is also acid-catalyzed, we then developed a one-pot procedure from triol 19 to acetal 18. In the event, we found that after completion of the CSA-catalyzed isomerization of triol 19, addition of dimethylacetal 37 produced 18, which could be crystallized to high enantiopurity ( $96 \%$ ee). To our further delight, oxidation of $\mathbf{1 8}$ with DDQ cleanly generated epoxide 39, presumably through the intermediacy of oxonium species 38. To the best of our knowledge, this represents the first synthesis of an epoxide from a 1,2-diol using this approach. ${ }^{[18-19]}$ While this process could be further telescoped by in situ methanolysis of the resulting benzoate, we found that the depicted two-step procedure to give alcohol $\mathbf{4 0}$ was more reliable and provided cleaner material. Ley-Griffith oxidation (TPAP/NMO) of the primary hydroxyl group in $\mathbf{4 0}$ gave aldehyde 17, which was subjected to Wittig homologation ${ }^{[20]}$ to give $\mathbf{4 2}$, followed by Horner-Wadsworth-Emmons olefination and reduction to give alcohol 44. Manganese dioxide oxidation gave 45, a compound known as verrucosal, ${ }^{[21]}$ which then underwent Stork-Zhao olefination to produce Stille coupling partner iodide 12.
To complete the synthesis of the emeriones, the two enantioenriched fragments $\mathbf{1 2}$ and $\mathbf{1 3}$ were combined in a Stille coupling to give pentaene 9 (Scheme 2). Stille conditions using $\mathrm{Pd}_{2} \mathrm{dba}_{3} / \mathrm{P}(2 \text {-furyl })_{3} / \mathrm{Cul}$ or the Liebeskind variant using CuTC/Pd( $\left(\mathrm{PPh}_{3}\right)_{4}$ both successfully delivered product. Fluoride additives (e.g. CsF) could not be used as they promoted retroaldol reaction. Interestingly, 9 proved to be quite stable at room temperature: it could be isolated via column chromatography and spectroscopically analyzed with no apparent isomerization or decomposition. Upon heating in toluene at $55{ }^{\circ} \mathrm{C}, 9$ slowly $(3 \mathrm{~d})$ isomerized into a roughly equimolar mixture of $\mathbf{1 0}$ and $\mathbf{1 1}$, as estimated by ${ }^{1} \mathrm{H}$ NMR of the crude reaction mixture. ${ }^{[22]}$ This stereochemical outcome must arise first via conrotatory $8 \pi$ electrocyclization of 9 that proceeds with essentially no induced diastereocontrol to produce cyclooctatrienes 47 and $\mathbf{4 8}$. These diastereomers then each undergo highly selective $6 \pi$ disrotatory electrocyclizations to give 10 and $\mathbf{1 1}$, respectively. Pleasingly, 10 and 11 each underwent chemo and stereoselective epoxidation with $m$-CPBA at the least hindered of the three double bonds to give (-)-emerione A (1) and (-)-emerione B (2), respectively. Spectroscopic and optical rotation data were consistent with the values reported for the naturally occurring materials (Tables S1-S2). 
When an $\mathrm{O}_{2}$-saturated dichloroethane solution of 11 and the triplet sensitizer methylene blue was irradiated $(400 \mathrm{~W}$, white halogen lamp), a single endoperoxide adduct (50) was formed within $10 \mathrm{~min}$. We expected $\mathbf{5 0}$ to be (-)-emerione C; however, upon comparison of NMR spectra of $\mathbf{5 0}$ and the reported data for emerione C (Figure 3A, Table S4), it was clear that the two substances, while very similar, are different. ${ }^{[2]}$ We therefore treated 10 under identical ${ }^{1} \mathrm{O}_{2}$-producing conditions to cleanly give endoperoxide 49. This compound had NMR spectra that were identical with those reported for emerione C (Figure 3B, Table S3), strongly indicating that emerione $C$ shares the same stereochemical backbone configuration as emerione A. To unambiguously clarify the chemical structures, we solved the structure of $\mathbf{5 0}$ by X-ray crystallography (Figure $3 \mathrm{C}$ ), and found that it has the structure that was originally proposed for emerione $\mathrm{C}$. We, therefore, reassign the structure of emerione $\mathrm{C}$
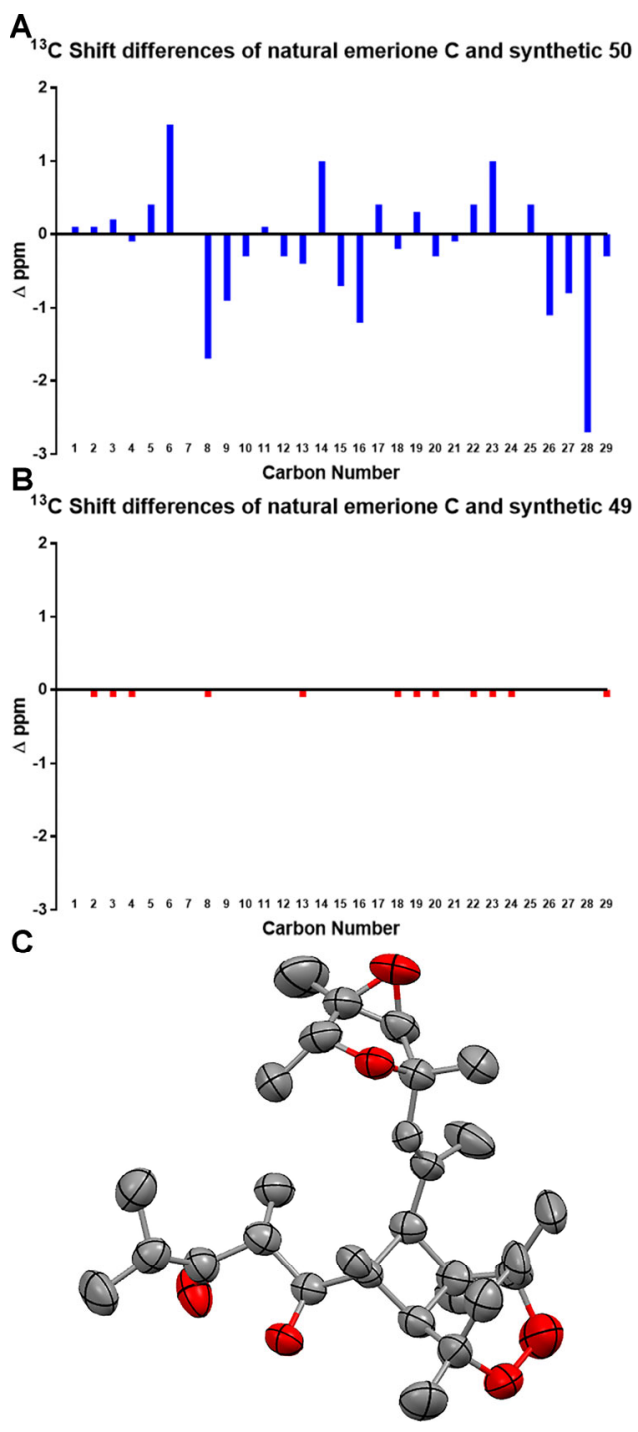

Figure 3. A. Comparison of ${ }^{13} \mathrm{C}$ shifts between emerione $\mathrm{C}$ and 50 . B. Comparison of ${ }^{13} \mathrm{C}$ shifts between emerione $\mathrm{C}$ and 49. C. Experimental structure of (+)-emerione D (50). Ellipsoids depicted at a $50 \%$ probability level. ${ }^{13}$ Color code: carbon, grey; oxygen, red.
(49) as it is depicted in Scheme 2 and name compound $\mathbf{5 0 ,}$ which we think is not unlikely to also be a natural product, (+)-emerione D.

In conclusion, we have successfully implemented an asymmetric bioinspired synthesis of all three emeriones, each with a longest linear sequence of 17 steps. Our synthesis has resulted in the reassignment of the structure of emerione $\mathrm{C}$; we also prepared the originally proposed structure of emerione $\mathrm{C}$, and renamed it emerione $\mathrm{D}$. Our approach is convergent, cutting a pentaene intermediate roughly in half, with both chiral side chains prepared in enantioenriched form. Attempting to limit our use of protecting groups led us to an efficient and novel oxidative epoxide-forming reaction. As biological data of the emeriones has only been reported with one type of assay, current efforts in our lab aim to discover biological activities of these fascinating substances.

\section{Acknowledgements}

We thank Dr. Karel Klika and Ms. Gabriele Schwebel for NMR support, and Dr. Frank Rominger for X-ray structure analysis. A.K.M. thanks the DKFZ and the Helmholtz Drug Research Initiative for support.

Keywords: Electrocyclizations $\cdot$ Cascade reactions $\bullet$ Total synthesis $\cdot$ Polyketides $•$ Biomimetic synthesis

[1] For a comprehensive review of electrocyclizations in biomimetic synthesis, see: (a) C. M. Beaudry, J. P. Malerich, D. Trauner Chem. Rev. 2005, 105, 4757-4778; For total synthesis approaches toward the endiandric acids, see: (b) K. C. Nicolaou, N. A. Petasis, R. E. Zipkin, J. Uenishi J. Am. Chem. Soc. 1982, 104, 5555-5557; (c) K. C. Nicolaou, N. A. Petasis, J. Uenishi, R. E. Zipkin J. Am. Chem. Soc. 1982, 104, 5557-5558; (d) K. C. Nicolaou, R. E. Zipkin, N. A. Petasis J. Am. Chem. Soc. 1982, 104, 5558-5560; (e) K. C. Nicolaou, N. A. Petasis, R. E. Zipkin J. Am. Chem. Soc. 1982, 104, 55605562; (f) S. L. Drew, A. L. Lawrence, M. S. Sherburn Chem. Sci. 2015, 6, 3886-3890; (g) O. Yahiaoui, A. Almass, T. Fallon Chem. Sci. 2020, 11, 9421-9425; For the SNF4435 compounds, see: (h) K. A. Parker, Y.-H. Lim J. Am. Chem. Soc. 2004, 126, 15968-15969; (i) C. M. Beaudry, D. Trauner Org. Lett. 2005, 7, 4475-4477; (j) M. F. Jacobsen, J. E. Moses, R. M. Adlington, J. E. Baldwin Org. Lett. 2005, 7, 2473-2476; For the elysiapyrones and ocellapyrones, see: (k) J. E. Barbarow, A. K. Miller, D. Trauner Org. Lett. 2005, 7, 29012903; (I) A. K. Miller, D. Trauner Angew. Chem. Int. Edit. 2005, 44, 4602-4606; (m) J. E. Moses, R. M. Adlington, R. Rodriguez, S. J. Eade, J. E. Baldwin Chem. Comm. 2005, 1687-1689; (n) R. Rodriguez, R. M. Adlington, S. J. Eade, M. W. Walter, J. E. Baldwin, J. E. Moses Tetrahedron 2007, 63, 4500-4509; For the shimalactones, see: (o) V. Sofiyev, G. Navarro, D. Trauner Org. Lett. 2008, 10, 149-152; For the kingianins, see: (p) S. L. Drew, A. L. Lawrence, M. S. Sherburn Ang. Chem. Int. Ed. 2013, 52, 4221-4224; (q) H. N. Lim, K. A. Parker Org. Lett. 2013, 15, 398-401; (r) J. C. Moore, E. S. Davies, D. A. Walsh, P. Sharma, J. E. Moses Chem. Comm. 2014, 50, 12523-12525; For PF-1018, see: (s) H. Quintela-Varela, C. S. Jamieson, Q. Shao, K. N. Houk, D. Trauner Angew. Chem. Int. Ed. 2020, 59, 5263-5267.

[2] Q. Li, C. Chen, Y. He, D. Guan, L. Cheng, X. Hao, M. Wei, Y. Zheng, C. Liu, X.-N. Li, Q. Zhou, H. Zhu, Y. Zhang Org. Lett. 2019, 21, 5091-5095.

[3] (a) S. Hatakeyama, K. Sakurai, H. Numata, N. Ochi, S. Takano J. Am. Chem. Soc. 1988, 110, 5201-5203; (b) K. Whang, R. J. Cooke, G. Okay, J. K. Cha J. Am. Chem. Soc. 1990, 112, 8985-8987. 
[4] H. Fujimoto, K. Yamamoto, M. Arisawa, S. Takahashi, Y. Tanaka, M. Yamazaki Mycotoxins 1998, 1998, 29-34.

[5] NMR was the sole technique used to determine the relative configuration of emecorrugatin B. In light of the discovery of the emeriones, and because the aldol portion of emecorrugatin $B$ is quite remote to other stereocenters, we consider it not unlikely that emecorrugatin $\mathrm{B}$ has the structure depicted as 7 .

[6] A. Patel, K. N. Houk J. Org. Chem. 2014, 79, 11370-11377.

[7] I. Paterson, D. J. Wallace, C. J. Cowden Synthesis 1998, 639652.

[8] M. Magnin-Lachaux, Z. Tan, B. Liang, E.-i. Negishi Org. Lett. 2004, 6, 1425-1427.

[9] Attempts to capture the samarium enolate in the absence of methanol as a co-solvent with a variety of methyl electrophiles was unsuccessful.

[10] P. Waser, K.-H. Altmann Angew. Chem. Int. Ed. 2020, 59 , 17393-17397.

[11] Due to the large quantities of Still-Gennari reagent 31 that were required to perform this reaction, and the lack of a convenient and reliable large-scale synthesis of $\mathbf{3 1}$, we also investigated the Ando reagent, which can be easily prepared on centagram scale (see reference 12). Unfortunately, we obtained lower diastereoselectivies with the Ando reagent.

[12] R. K. Bressin, J. L. Driscoll, Y. Wang, K. Koide Org. Process Res. Dev. 2019, 23, 274-277.

[13] CCDC 2144886 (36), CCDC 2144887 (25), and CCDC $2144888(50)$ contain the supplementary crystallographic data for this paper. The data can be obtained free of charge from The Cambridge Crystallographic Data Centre via www.ccdc.cam.ac.uk/structures.

[14] Quantified via NMR of the corresponding Mosher ester.

[15] (a) F. Narjes, E. Schaumann Liebigs Ann. Chem. 1993, 841846; (b) P. Wipf, P. C. Fritch J. Org. Chem. 1994, 59, 48754886; (c) N. A. Setterholm, F. E. McDonald J. Org. Chem. 2018, 83, 6259-6274; (d) Y.-Q. Zhang, C. Poppel, A. Panfilova F. Bohle, S. Grimme, A. Gansaeuer Angew. Chem. Int. Ed. 2017, 56, 9719-9722.

[16] The ee was determined via Mosher ester analysis after first converting $\mathbf{1 9}$ to $\mathbf{4 0}$ (with no crystallization steps).

[17] Y. Oikawa, T. Nishi, O. Yonemitsu J. Chem. Soc. Perk. Trans. 11985, 7-17.

[18] D. R. Williams, Y. Harigaya, J. L. Moore, A. D'Sa J. Am. Chem. Soc. 1984, 106, 2641-2644.

[19] (a) T. Zheng, R. S. Narayan, J. M. Schomaker, B. Borhan J. Am. Chem. Soc. 2005, 127, 6946-6947; (b) M. J. Begley, M. C. Bowden, P. Patel, G. Pattenden J. Chem. Soc. Perk. Trans. 1 1991, 1951-1958; (c) H. Tanabe, X. He, P. Kothandaraman, M. Yamane Synlett 2010, 1190-1192.

[20] Attempts to perform a double Wittig homologation to directly prepare $\mathbf{4 5}$ were plagued by inseparable mixtures of single (42), double (45), and triple (not shown) homologations.

[21] L. L. Klein Tet. Lett. 1986, 27, 4545-4548.

[22] The two products could only be partially separated by careful preparative TLC, which is reflected in the relative modest yields of $\mathbf{1 0}$ and $\mathbf{1 1}$. The remaining mass balance is primarily contained in mixed fractions, which were not further separated. 


\section{Entry for the Table of Contents}

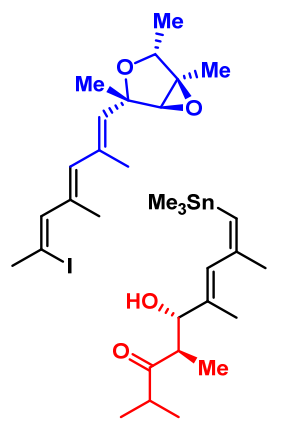
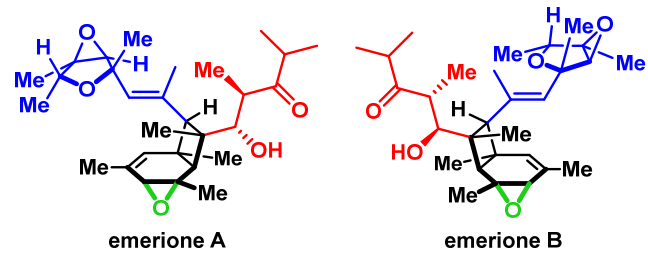

$-8 \pi / 6 \pi \rightarrow$

then

late-stage

[O]

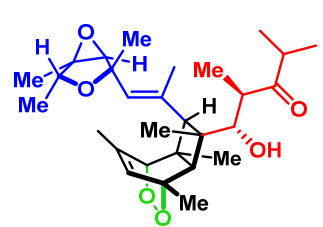

emerione

revised structure

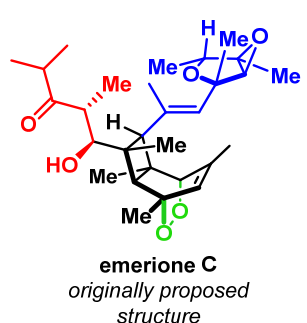

The emeriones, three highly-oxidized and densely functionalized polyketides, were synthesized from two enantioenriched polyene fragments in a Stille/ $8 \pi / 6 \pi$ cascade, followed by late-stage stereo and chemoselective oxidations. This work enabled the structural revision of emerione $\mathrm{C}$.

@DrugDiscov_DKFZ 